\title{
Current Microbial Isolates from Wound Swab and Their Susceptibility Pattern in a Private Medical College Hospital in Dhaka city
}

\author{
Shahin Sultana ${ }^{1}$, Nurunnahar Mawla ${ }^{2}$, Shamima Kawser ${ }^{3}$, \\ Nayareen Akhtar ${ }^{4}$, Md. Khoybar Ali ${ }^{5}$
}

\begin{abstract}
Background: Wound infection is one of the major health problems that are caused and aggravated by the invasion of pathogenic organisms where empiric treatment is routine. Objective: To isolate and identify the bacteria causing wound infection and to determine the antimicrobial susceptibility pattern. Materials and method: A total of 263 wound swab and pus samples were collected during the period of January to December 2012 from Delta Medical College and Hospital, Dhaka, Bangladesh. Swabs from the wound were inoculated on appropriate media and cultured and the isolates were identified by standard procedures as needed. Antimicrobial susceptibility testing was performed by disk diffusion method according to 'The Clinical Laboratory Standard Institute' guidelines. Results: In this study 220 bacterial isolates were recovered from 263 samples showing an isolation rate of $83.65 \%$. The predominant bacteria isolated from infected wounds were Staphylococcus aureus 89 (40.45\%) followed by Escherichia coli 62 (28.18\%), Pseudomonas aeruginosa 34 (15.45\%), Enterococci 18 (8.18\%), Acinetobacter 5 (2.27\%), Klebsiella 9 (4.09\%) and Proteus 3 (3.36\%). Staphylococcus aureus was sensitive to linezolid (94.38\%), fusidic acid (91.01\%), vancomycin (87.64\%), amikacin (74.15\%) and gentamicin (73.03\%). Among the Gram negative isolates Escherichia coli was predominant and showed sensitivity to imipenem (93.54\%) amikacin (83.87\%) colistin (53.22\%) and piperacillin and tazobactum (53.22\%) and pseudomonas showed sensitivity to amikacin (73.52\%), imipenem (70.58\%) and colistin (70.58\%). Conclusion: Staphylococcus aureus was the most frequently isolated pathogen from wound swab and the antibiotic sensitivity pattern of various isolates help to assist the clinician in appropriate selection of empirical antibiotics against wound infection.
\end{abstract}

Key words: Wound swab; isolation of bacteria; antimicrobial sensitivity pattern.

Delta Med Col J. Jan 2015;3(1):25-30

\section{Introduction}

A wound is the disruption in the continuity of soft parts of the body structures. ${ }^{1,2}$ Development of wound infection depends on the many factors including preexisting illness, length of operation, wound class and contamination. ${ }^{3-5}$ Infection of the wound is the invasion and proliferation by one

1. Associate Professor \& Head, Dept. of Microbiology, Delta Medical College, Dhaka, Bangladesh.

2. Assistant Professor, Dept. of Microbiology, Delta Medical College, Dhaka, Bangladesh.

3. Associate Professor \& Head, Dept. of Microbiology, Dr. Sirajul Islam Medical College, Dhaka, Bangladesh.

4. Assistant Professor, Dept. of Microbiology, Delta Medical College, Dhaka, Bangladesh.

5. Associate Professor \& Head, Dept. of Paediatrics, IBN Sina Medical College, Dhaka, Bangladesh.

Correspondence: Dr. Shahin Sultana. e-mail: shahinsultana1998@gmail.com 
or more species of microorganisms sometimes resulting in pus formation. ${ }^{6}$ Wound can be infected by a variety of microorganisms ranging from bacteria to fungus and parasites. ${ }^{7}$

The common organisms that have been associated with wound infection include Staphylococcus aureus which from various studies have been found to account for 20-40\%. Infection with Pseudomonas aeruginosa mainly following surgery and burns account for 5-15\%. Other pathogens such as Enterococci, Escherichia coli, Klebsiella species and Proteus species have been implicated especially in immunocompromised patients and following abdominal surgery. ${ }^{8}$ The fungal organisms are Candida species also responsible for wound infection. ${ }^{9}$ Different microorganisms can exist in polymicrobial communities especially in the margins of wounds and in chronic wounds. ${ }^{10}$ The resistance of the hospital strains of S. aureus to methicillin remains a global problem so the control of wound infections has become more challenging. ${ }^{11}$ As a result of indiscriminate use of antimicrobial agents, significant changes occur in microbial genetic echology. So spread of antimicrobial resistance is now a global problem. ${ }^{12}$

The aim of the present study was to find out common bacterial pathogens responsible for wound infection and to determine their antimicrobial susceptibility pattern in our community. It would assist the clinicians in appropriate selection of antibiotics especially against hospital acquired infections.

\section{Materials and method}

This study was carried out by collecting wound swabs and pus samples from patients attending at Delta Medical College and Hospital, Dhaka, Bangladesh from January to December 2012. All the samples were cultured on blood agar and MacConkey agar media incubated overnight at $37^{\circ} \mathrm{C}$. Organisms were identified by standard microbiological procedures including colony characters, Gram staining and biochemical reactions. 13 All the isolates were tested for antimicrobial susceptibility by the disc diffusion technique according to the Clinical Laboratory Standards Institute (CLSI) guidelines. ${ }^{14,15}$

\section{Results}

Out of 263 cases $174(66.15 \%)$ were male and 89 $(33.84 \%)$ were female and the age ranged between 3 months to 91 years A total number of 220 isolates were obtained, among which 185 (70.34\%) were culture positive cases.

Among the isolated organisms predominant bacteria was Staphylococcus aureus 89 (40.45\%) followed by Escherichia coli 62 (28.18\%), Pseudomonas aeruginosa 34 (15.45\%), Enterococci 18 (8.18\%), Klebsiella 9 (4.09\%), Acinetobacter 5 (2.27\%) and Proteus 3 (3.36\%) (Table I).

Table I: Organisms isolated from wound swab

\begin{tabular}{lcc}
\hline Organisms & $\begin{array}{c}\text { Number } \\
(\mathbf{N}=\mathbf{2 2 0})\end{array}$ & Proportion (\%) \\
\hline Gram positive cocci & 89 & 40.45 \\
Staphylococcus aureus & 18 & 8.18 \\
Enterococci & & \\
Gram negative bacilli & 62 & 28.81 \\
Escherichia coli & 34 & 15.45 \\
Pseudomonas aeruginosa & 09 & 4.09 \\
Klebsiella & 05 & 2.27 \\
Acinetobacter & 03 & 1.36 \\
Proteus & & \\
\hline
\end{tabular}

All the bacterial isolates were tested for antimicrobial susceptibility. Among the Gram positive isolates Staphylococcus aureus was the predominant organism and were found highly sensitive to linezolid (94.38\%), fusidic acid (91.01\%), vancomycin (87.64\%), amikacin $(74.15 \%)$, and gentamicin $(73.03 \%)$ and low sensitivity were found in commonly used antibiotics like ciprofloxacin (32.58\%), cloxacillin (28.08\%), ceftriaxone (28.08\%), ceftazidime $(24.71 \%)$ and cotrimoxazole (21.34\%). Enterococci showed highest sensitivity to linezolid, vancomycin and fusidic acid and which was $88.88 \%$. Lowest sensitivity was found 
to cephalexin $(17.97 \%)$, cephradine $(15.73 \%)$ and cefixime (10.11\%) (Table II).

Table II: Antibiotic susceptibility pattern (percent sensitive) of gram positive cocci

\begin{tabular}{lcc}
\hline Antibiotics & $\begin{array}{c}\text { Staphylococcus } \\
\text { aureus (\%) }\end{array}$ & Enterococcus (\%) \\
\hline Amikacin & 74.15 & 16.66 \\
Imipenem & 22.47 & 66.66 \\
Gentamicin & 73.03 & 27.77 \\
Cloxacillin & 28.08 & 72.22 \\
Ciproflaxacin & 32.58 & 55.55 \\
Cefixime & 10.11 & 66.66 \\
Ceftriaxone & 28.08 & 66.66 \\
Ceftazidime & 24.71 & 66.66 \\
Cephradine & 15.73 & 66.66 \\
Cephalexin & 17.97 & 66.66 \\
Co-trimoxazole & 21.34 & 38.38 \\
Linezolid & 94.38 & 88.88 \\
Vancomycin & 87.64 & 88.88 \\
Fusidic acid & 91.01 & 88.88 \\
\hline
\end{tabular}

Among the Gram negative isolates Escherichia coli was the predominant organism followed by Pseudomonas aeruginosa and Klebsiella. The sensitivity of Escherichia coli to imipenem was $93.54 \%$, amikacin $83.87 \%$, colistin $53.22 \%$ and piperacillin + tazobactum $53.22 \%$ and low level of sensitivity was found to co-trimoxazole (30.64\%) and ciprofloxacin $(29.03 \%)$. Other drugs like ceftriaxone, cefixime, ceftazidime and cephradine

Table III: Antibiotic susceptibility pattern (percent sensitive) of gram negative bacilli

\begin{tabular}{lccc}
\hline Antibiotics & E. coli (\%) & $\begin{array}{c}\text { Pseudomonas } \\
\text { aeruginosa(\%) }\end{array}$ & Klebsiella (\%) \\
\hline Amikacin & 83.87 & 73.52 & 77.77 \\
Imipenem & 93.54 & 70.58 & 77.77 \\
Gentamicin & 48.38 & 44.11 & 55.55 \\
Tazobactam+Pipracillin & 51.61 & 35.29 & 55.55 \\
Colistin & 53.22 & 70.58 & 55.55 \\
Ciprofloxacin & 29.03 & 47.09 & 44.44 \\
Co-trimoxazole & 30.64 & 14.7 & 33.33 \\
Cephalexin & 12.90 & 5.88 & 11.11 \\
Cephradine & 3.22 & 0 & 11.11 \\
Cefixime & 6.45 & 0 & 11.11 \\
Ceftazidime & 6.45 & 5.88 & 0 \\
Ceftriaxone & 8.06 & 0 & 11.11 \\
\hline
\end{tabular}

showed lowest sensitivity below $10 \%$. Pseudomonas showed lowest sensitivity to almost all of the drugs except amikacin which was $73.52 \%$ sensitive. Almost similar sensitivity was shown to imipenem and colistin which was $70.58 \%$. Klebsiella showed $77.77 \%$ sensitivity to amikacin and imipenem and $55.55 \%$ sensitivity to gentamicin, piperacillin + tazobactum and colistin (Table III).

\section{Discussion}

Bacterial contamination of wounds is a serious problem in the hospital especially in surgical practice where the site of a sterile operation can become contaminated and subsequently infected. ${ }^{16}$

Inspite of proper application of the basic principles of wound care a number of patients develop infections needing proper identification of the organisms for appropriate management. ${ }^{17} \mathrm{~A}$ changing pattern of isolated organisms and their antimicrobial sensitivity varies from hospital to hospital and region to region is a usual feature. In our study, Staphylococcus aureus was the most predominant pathogenic bacteria from wound sample which was similar to the other studies done by Shriyan et al. ${ }^{18}$, Noroozi et al. ${ }^{19}$, Isibor et al. ${ }^{20}$, Siguan et al. ${ }^{17}$ and Anbumani et al. ${ }^{21}$ Predominance of Staphylococcus aureus is however not surprising as it forms the bulk of the normal flora of the skin and nails. ${ }^{20}$ Escherichia coli was the next common organism followed by Pseudomonas aeruginosa, Enterococci and Klebsiella which was similar to other studies done by Verma et al. ${ }^{18}$ and Albumani et al. ${ }^{21}$ This confirms that most wound infections arising from abdominal procedures are acquired from patients own faecal flora. ${ }^{20}$

In our study, Staphylococcus aureus showed $94.38 \%$ sensitive to linezolid, $91.01 \%$ to fusidic acid followed by $87.64 \%$ to vancomycin, $74.15 \%$ to amikacin, and $73.03 \%$ to gentamicin and less sensitivity were found in commonly used antibiotic like ciprofloxacin $(32.58 \%)$, cloxacillin (28.08\%), ceftriaxone $(28.08 \%)$, ceftazidime $(24.71 \%)$ and cotrimoxazole (21.34\%). Lowest 
sensitivity was found to cephalexin (17.97\%), cephradine (15.73\%) and cefixime (10.11\%). A study had shown $100 \%$ sensitivity to linezolid and vancomycin followed by gentamicin (88.88\%). ${ }^{22-24}$ Another study showed complete sensitivity to vancomycin, linezolid, fusidic acid and amikacin 24,25 and low activities against co-trimoxazole, ciprofloxacin, tetracycline and erythromycin. ${ }^{26-29}$ Above two findings are near about similar to our findings.

Remarkable susceptibility of Staphylococcus aureus to vancomycin, linezolid, fusidic acid, amikacin and gentamicin may be due to lesser use of these antibiotics as a result of their less availability, cost and toxic effect. ${ }^{30}$ Low activities of commonly used antibiotics such as cotrimoxazole, cloxacillin, ceftriaxone, ceftazidime, cephalexin cephradine and cefixime may be due to increased consumption of a particular antibiotic which leads to the development of resistance resulting from mutation at drug target sites, or from the disturbance of drug accumulation in cytoplasm due to cell wall or cell membrane rearrangement. ${ }^{31-34}$ As a result, they have lost their efficacy in the treatment of wound infection.

E. coli were sensitive to amikacin $85.87 \%$, imipenem 93.54\%, tazobactam + piperacillin $51.61 \%$ and colistin $53.22 \%$ which was similar to the study done by Mahmood et al. ${ }^{25}$ Ranjan et al. ${ }^{35}$ reported that Gram negative isolates were found to be most susceptible to imipenem $(90.76 \%)$ followed by piperacillin + tazobactam $(68.46 \%)$ and amikacin (73.84\%). Pseudomonas aeruginosa isolates were susceptible to imipenem (70.58\%), amikacin $(73.52 \%)$, colistin $(70.58 \%)$. But the study done by Anbumani et al. ${ }^{21,22}$ had shown variable susceptibility pattern with imipenem $100 \%$, piperacillin + tazobactum $(87.71 \%)$, levofloxacin $(85.71 \%)$, cefotaxime $(71.42 \%)$ for Pseudomonas aeruginosa.

Klebsiella showed highest sensitivity to amikacin and imipenam $(77.77 \%)$, gentamicin, piperacillin + tazobactum and colistin (55.55\%) and lowest sensitivity to ceftriaxone, cephradine, Cephalexin and cefixime $(11.11 \%)$ and $100 \%$ resistance to ceftazidime which was similar to the study done by Anbumani et al. ${ }^{21}$ and Anderl et al. ${ }^{36}$

The findings of our study show that Staphylococcus aureus was found to be the predominant among all of the isolates of wound infections and showed highest sensitivity to vancomycin, linezolid and fusidic acid followed by amikacin. Most of the Gram negative isolates were highly sensitive to imipenem followed by amikacin, piperacillin + tazobactum and colistin. We should use these drugs rationally so that they remain effective for treatment of wound infection. As the commonly used drugs shows less sensitivity, further study is needed for newer drugs to fight against wound infection.

\section{References}

1. Mordi MR, Momoh MI. Incidence of Proteus Species in Wound Infections and their Sensitivity Pattern in the University of Benin Teaching Hospital. African Journal of Biotechnology. 2009;8(5):725-30.

2. Al-Tameemi HAAN, Khalaf JM. Isolation and Identification of Fungi from Wounds and Burns of Human and Farm Animals. The Iraqi Journal of Veterinary medicine. 2013;37(2):251-56.

3. Dellinger EP. Surgical Infections and Choice of Antibiotics. In: Sabiston DC, Lyerly K, editors. Text Book of Surgery: The Biological Basis of Modern Surgical Practice. 15th ed. Philadelphia: WB Saunders Company; 1997.p.264-80.

4. Nandi PL, Rajan SS, Mak KC, Chan SC, So YP. Surgical Wound Infection. Hong Kong Medical Journal. 1999;5:82-86.

5. Razavi SM, Ibrahimpoor M, Kashani AS, Jafarian A. Abdominal Surgical Site Infections: Incidence and Risk Factors at an Iranian Teaching Hospital. BMC. Surgery. 2005;5:2.

6. Mohammed A, Adeshina GO, Ibrahim YK. Incidence and Antibiotic Susceptibility Pattern of Bacterial Isolates from Wound Infections in a Tertiary Hospital in Nigeria. Tropical Journal of Pharmaceutical Research. 2013;12(4):617-21. 
7. Bowler P, Duerden B, Armstrong D. Wound Microbiology and Associated Approaches to Wound Management. Clin Microbiol Rev. 2001;14(2):244-69.

8. Taiwo S, Okesina A, Onile B. In Vitro Antimicrobial Susceptibility Pattern of Bacterila Isolates from Wound Infections in University of Ilorin Teaching Hospital. Afr J Clin Exp Microbiol. 2002;3(1):6-10.

9. Gunzalez G, Bronze MS, Drevets DA, Glatt A, Mylonakis E, Burke AC. Surgical Wound Infection [Internet]. 2006 [cited 2014 Aug 25]. Available from: http:// www.emedicine.MED/topic1929.htm.

10. Perceivil S, Bowler P. Understanding the Effects of Bacterial Communities and Biofilm on Wound Healing [Internet]. 2004 [cited 2014 Sep 5]. Available from: http:/www worldwidewound.com.

11. Alebachew T, Yismaw G, Derabe A, Sisay Z. Staphylococcus Aureus Burn Wound Infection among Patients attending Yekatit 12 Hospital Burn Unit, Addis Ababa, Ethiopia. Ethiop J Health Sci. 2012;22(3):209-13.

12. Goswami NN, Trivedi HR, Goswami APP, Patel TK Tripathi CB. Antibiotic Sensitivity Profile of Bacterial Pathogens in Post Operative Wound Infections at a Tertiary Care Hospital in Gujrat India. Journal Pharmacology and Pharmacokinetics. 2011;2(3):158-62.

13. Collee JG, Miles RS, Watt B, Fraser AG, Marmion BP, Simonds A, editors. Test for Identification of Bacteria. In: Mackie and MC Cartney. Practical Medical Microbiology. 14th ed. NewYork: Churchill Livingstone; 1996.

14. CLSI. Performance Standards for Antimicrobial Susceptibility Testing: 21st Informational Supplements. CLSI document MI00-S21. Wayne PA: Clinical and Laboratory Standards Institute; 2011.

15. National Committee for Clinical Laboratory Standards Performance Standards for Antimicrobial Susceptibility Testing. 11th edition. Wayne PA; 2001.
16. Pondei K, Fente BG, Oledapo O. Current Microbial Isolates from Wound Swabs, Their Culture and Sensitivity Pattern at the Niger Delta University Teaching Hospital, Okolobiri, Nigeria. Trop Med Health. 2013;41(2):49-53.

17. Siguan SS, Ang BS, Pala IM, Baclig RM. Aerobic Surgical Infection: A Surveillance on Microbiological Etiology and Antimicrobial Sensitivity Pattern of Commonly Used Antibiotics. Phil J Microbial Infect Dis. 1990;19(1):27-33.

18. Shriyan A, Sheetal R, Nayak N. Aerobic Micro-Organisms in Post-operative Wound Infections and Their Antimicrobial Susceptibility Patterns. Journal of Clinical and Diagnostic Research. 2010;4:3392-96.

19. Noroozi H, Kazemi A, Fadaee R, Alavi S, Mohammadzadeh M. Microbiologic Assessment of Non-Surgical Traumatic Wound Infection. and Surgical Site Infections in Hospitalized Patients. Iranian Journal of Clinical Infections Diseases. 2010;5(2):80-83.

20. Isibor JO, Osani A, Eyaufe A, Osagie R, Turay A. Incidence of Aerobic Bacteria and Candida Albicans in Post-operative Wound Infection. African Journal of Microbiology Research. 2008;2(1):288-91.

21. Anbumani N, Kalyani J, Mallika M. Epidemiology and Microbiology of Wound Infections. Indmedica-Indian Journal for the Practising Doctor. 2006;3(5):11-12.

22. Lalithambigai J, Kavitha A, Priyadharsini RI, Rajesh KR. Postoperative Wound Infections and Their Antimicrobial Susceptibility Pattern in a Tertiary Care Hospital in Salem, India. International Journal of Research in Pharmacology \& Pharmacotherapeutics. 2014;3(1):46-52.

23. Goswami N, Trivedi HR, Goswami APP. Antibiotic Sensitivity Profile of Bacterial Pathogens in Postoperative Wound Infections at a Tertiary Care Hospital in Gujarat, India. J Pharm Pharm. 2011;2(3):158-64. 
24. Manikandan C, Amsath A. Antibiotic Susceptibility of Bacterial Strains Isolated from Wound Infection Patients in Pattukkottai, Tamilnadu, India. Int J Curr Microbiol App Sci. 2013;2(6):195-203.

25. Mahmood A. Bacteriology of Surgical Site Infections and Antibiotic Susceptibility Pattern of the Isolates at a Tertiary Care Hospital in Karachi. PMA. 2000;50:256.

26. Kawai M, Yamada S, Ishidoshiro A, Oyamada Y, Ito H, Yamagishi J. Cell-wall thickness: Possible Mechanism of Acriflavine in Methicillin-Resistant Staphylococcus aureus. J Med Microbiol. 2009;58:331-36.

27. Kwong SM, Lim R, Lebard RJ, Skurray RA, Firth N. Analysis of the pSK1 Replicon, a Prototype from the Staphylococcal Multi-Resistance Plasmid Family. Microbiology. 2008;154:3084-94.

28. Memmi G, Filipe SR, Pinho MG, Fu Z, Cheung A. Staphylococcus aureus PBP4 is Essential or Beta-lactam Resistance in Community-Acquired Methicillin-Resistant Strains. Antimicrob Agents Chemothe. 2008;52:3955-66.

29. Xu H, Sullivan TJ, Sekiguchi J, Kirikae T, Ojima I, Stratton CF, et al. Mechanism and Inhibition of saFabI, the Enoyl Reductase from Staphylococcus aureus. Biochemistry. 2008;47:4228-36.
30. Mama M, Adissa A, Sewunet T. Antimicrobial Susceptibility Pattern of Bacterial Isolates from Wound Infection and Their Sensitivity to Alternative Topical Agents at Jimma University Specialized Hospital, South-West Ethiopia. Annals of Clinical Microbiology and Antimicrobials. 2014;13:14.

31. Barker KF. Antibiotic Resistance: A Current Perspective. Br J Clin Pharmacol. 1999;48:109-24.

32. Gold HS, Pillai SK. Antistaphylococcal Agents. Infect Dis Clin North Am. 2009;23:99-131.

33. Pinho MG, de Lencastre H, Tomasz A. An Acquired and a Native Penicillin-Binding Protein Cooperate in Building the Cell Wall of Drug-Resistant Staphylococci. Proc Natl Acad Sci USA. 2001;98:10886-91.

34. Speer BS, Shoemaker NB, Salyers A. Bacterial Resistance to Tetracycline Mechanisms, Transfer, and Cinical Significance. Clin Microbiol Rev. 1992;5:387-99.

35. Ranjan KP, Ranjan N, Bansal SK, Arora DR. Prevalence of Pseudomonas aeruginosa in Post-Operative Wound Infection in a Referral Hospital in Haryana, India. Journal of Laboratory Physicians. 2010;2(2):74-77.

36. Anderl JN, Franklin MJ, Stewart PS. Role of Antibiotic Penetration Limitation in Klebsiella pneumonia Biofilm Resistance to Ampicillin and Ciprofloxacin. Antimicrobial Agents and Chemotherapy. 2000;44(7):1818-24. 